Communicative eye contact signals a commitment to cooperate for young children

\author{
Barbora Siposova $^{1,2}$, Michael Tomasello ${ }^{2,3}$, and Malinda Carpenter ${ }^{1,2}$ \\ ${ }^{1}$ School of Psychology and Neuroscience, University of St Andrews, St Andrews, Scotland, UK \\ ${ }^{2}$ Department of Developmental and Comparative Psychology, Max Planck Institute for \\ Evolutionary Anthropology, Leipzig, Germany \\ ${ }^{3}$ Department of Psychology and Neuroscience, Duke University, Durham, NC, USA
}

Correspondence should be addressed to Barbora Siposova, Department of Psychology, University of Warwick, Coventry, CV4 7AL, UK. E-mail: barbora.siposova@warwick.ac.uk

Accepted version, in press, Cognition 


\begin{abstract}
Making commitments to cooperate facilitates cooperation. There is a long-standing theoretical debate about how promissory obligations come into existence, and whether linguistic acts (such as saying "I promise") are a necessary part of the process. To inform this debate we experimentally investigated whether even minimal, nonverbal behavior can be taken as a commitment to cooperate, as long as it is communicative. Five- to 7-year-old children played a Stag Hunt coordination game in which they needed to decide whether to cooperate or play individually. During the decision-making phase, children's partner made either ostensive, communicative eye contact or looked non-communicatively at them. In Study 1 we found that communicative looks produced an expectation of collaboration in children. In Study 2 we found that children in the communicative look condition normatively protested when their partner did not cooperate, thus showing an understanding of the communicative looks as a commitment to cooperate. This is the first experimental evidence, in adults or children, that in the right context, communicative, but not non-communicative, looks can signal a commitment.
\end{abstract}

Keywords: communicative eye contact, commitment, nonverbal communication, cooperation, coordination, Stag hunt game 


\section{Communicative eye contact signals a commitment to cooperate for young children}

\section{Introduction}

Successful cooperation enables individuals to achieve greater goals than would be possible on their own. However, entering into cooperative interactions carries risks. The classic example is that if many people participate in a public demonstration, they can create change, but if only a few people participate, their effort may be wasted and they may be put in danger. As a potential demonstrator, before one takes the risk of showing up to participate, one needs to judge whether others will participate too. To reduce uncertainty about others' behavior in cooperative interactions, communication and commitments are particularly useful tools (Michael \& Pacherie, 2015). It has been shown that exchanging verbal commitments substantially increases successful cooperation in social dilemmas among adults (for a meta-analysis, see Sally, 1995).

Typically, commitments arise verbally through speech acts of promising or making agreements. For example, Peter can commit himself to washing the dishes after dinner by promising his wife he will do so. He then has an obligation to wash the dishes and his wife has the right to protest if he does not. Although different definitions of commitments exist, most involve this general formulation: If one social partner intentionally communicates to another that he intends to do X, and the other acknowledges this, then they have common knowledge about this interaction, and the first partner is committed to do X (e.g., Austin, 1975; Searle, 1969; Scanlon, 1998).

There is considerable debate among philosophers about how one key type of commitments, promises, function. The main point of contention is the explanation of how promissory obligations come into existence. Conventionalist theories argue that promising is a 
social practice involving convention, and that only certain verbal statements (e.g., "I promise to do X" or "I will do X") or conventional acts (e.g., nodding) under the right circumstances will create promissory obligations (Hume, 1739-1740/1969; Kolodny \& Wallace, 2003; Rawls, 1955; Searle, 1969). In contrast, most contemporary accounts reject the idea that the core of promises is rooted in social convention (Gilbert, 2004; Owens, 2006; Scanlon, 1998; Shiffrin, 2008). For example, Scanlon (1998) argues that whenever one individual intentionally leads another to expect that he will do $\mathrm{X}$ (and knows that the other wants to be assured of $\mathrm{X}$ ), he is committed to do X, as the general moral principle not to mislead others is in place. Similarly, MacCormick (MacCormick \& Raz, 1972) has stressed the role of reliance: If one individual has intentionally induced another to rely on him, then he is committed to follow through. This is especially evident when the other individual takes detrimental action for herself based on her expectations of the first individual's behavior. Somewhat differently, in a discussion of joint commitments, Gilbert $(1990,2004,2014)$ claims that promissory obligations are not necessarily moral obligations, but are sui generis form of normativity. In her view, commitments do not need to be construed verbally; they are created by each individual expressing readiness to be jointly committed under conditions of common knowledge.

Therefore, although perhaps the easiest way to create promissory obligations is to state, "I promise to X," these latter accounts suggest that commitments and promises could arise even without any words at all. It has been suggested that it would be useful to move away from the binary distinction between full-fledged verbal, explicit promises vs. not promises, and elucidate the full spectrum of promissory obligations (Shiffrin, 2008). Part of the debate is about what type of communication of an intention to bind oneself to do $\mathrm{X}$ is necessary to form promissory obligations (Gilbert, 2014; Owens, 2006; Scanlon, 1998; Shiffrin, 2008). To inform the theory in 
this area, we investigated empirically whether it is possible to commit oneself nonverbally, as long as intentional communication is involved (Raz, 1977).

To our knowledge, these ideas have never been tested empirically. We hypothesized that a communicative look is an especially good candidate for a minimal, nonverbal signal that might be powerful enough not only to promote expectations of cooperation, but also to create a commitment. This type of eye contact is ostensive (Sperber \& Wilson, 1986), bidirectional, public, and enables one to communicate a message under conditions of common knowledge (Carpenter \& Liebal, 2011), as long as the common ground is strong enough (Tomasello, 2008). Thus, within the context of a cooperative coordination problem, here we test whether communicative, versus non-communicative, eye contact can signal a commitment to cooperate.

We designed a game based on the Stag Hunt dilemma, an ideal model for studying social dilemmas in mutualistic contexts (Rousseau, 1754/1984; Skyrms, 2004). In the Stag Hunt parable, two hunters decide either to each hunt a rabbit (a certain but small prize) individually or to hunt a stag (a risky but big prize) together, if it is available. However, if just one partner decides to cooperate and hunt the stag and the other decides to hunt a rabbit (e.g., because he does not know the stag is available), the cooperating partner loses the chance to get anything. Thus, successful cooperation in this context faces two main challenges: First, to reduce uncertainty about the partner's knowledge (here, about the presence of the stag), and second, to reduce uncertainty about the partner's behavior (whether he will cooperate).

The first challenge is epistemological. It is not enough if each social partner knows individually that the cooperative option is available. Instead, successful coordination is facilitated by common knowledge (Chwe, 2001; Clark, 1996), that is, each partner needs to know that the other knows about the cooperative option, that the other knows he knows, etc., ad 
infinitum (e.g., Lewis, 1969). However, as the processing demands for even just a few levels of such recursive reasoning are high, it is likely that we use simpler shortcuts such as communication for creating common knowledge (Clark, 1996). It has been shown that adults (Brosnan, Wilson, \& Beran, 2012) and 4-year-old children (Duguid, Wyman, Bullinger, Herfurth-Majstorovic, \& Tomasello, 2014) spontaneously use verbal communication to achieve common knowledge and solve the Stag Hunt dilemma successfully. Some authors have proposed that common knowledge can be created by nonverbal signals like eye contact (Carpenter \& Liebal, 2011; Chwe, 2001; Gómez, 1996; Thomas, DeScioli, Haque, \& Pinker, 2014); however, empirical evidence for this in children or adults is scare. We are aware of only one such study: Wyman, Rakoczy, and Tomasello (2013) studied the ability of a communicative look with a smile to create common knowledge about the presence of the cooperative option in a Stag Hunt game. In this study, 4-year-old children were discouraged from communicating verbally while playing this game with an experimenter. In the control condition, when the cooperative option appeared, the experimenter monitored it - it was clear that she saw it - but she did not look at children, whereas in the experimental condition, she alternated gaze ostensively between the cooperative option and children's eyes while smiling. More children decided to cooperate in the experimental than the control condition, suggesting that this minimal nonverbal behavior established common knowledge about the availability of the cooperative option.

Wyman et al. (2013) thus provide the first hint that nonverbal signals can serve to create common knowledge in a collaborative decision-making situation. However, many open questions remain about what exactly caused children to behave differently in the two conditions of that study. For example, did the eye contact alone generate common knowledge or was it the communication inherent in the look and/or smile? It has been argued that one cannot truly share 
attention to something, or know something together with one's partner, without some form of communication - even if just a communicative look (Carpenter \& Liebal, 2011; Siposova \& Carpenter, in prep.). Thus in the current studies, our first aim was to test the hypothesis that communicative looks (but not non-communicative looks) help establish common knowledge about the cooperative option, and therefore lead children to expect cooperation from their partner and thus to decide to risk cooperation.

The second challenge for cooperation is to reduce uncertainty about one's partner's behavior, and it has been suggested that commitments and promises are a key way of stabilizing cooperative behavior (Michael \& Pacherie, 2015). Children begin to engage in collaborative activities with complementary roles and joint goals around two years of age (Brownell, 2011), but a basic understanding of commitments and at least some of the resulting obligations develops somewhat later, by the age of three - not coincidentally, at around the same age that children begin to show an understanding of social norms regarding moral transgressions (e.g., Smetana \& Braeges, 1990; Vaish, Missana, \& Tomasello, 2011), fairness (Smith, Blake, \& Harris, 2013), and simple game rules (Rakoczy, Warneken, \& Tomasello, 2008). For example, after verbally making a joint commitment to cooperate, 3-year-olds understand some of the obligations that both they and their partner have to keep playing (Gräfenhain, Behne, Carpenter, \& Tomasello, 2009) and protest when their partner intentionally defects (Kachel, Svetlova, \& Tomasello, 2017). Preschoolers also understand promissory obligations: They tend to keep their own promises and refer to the promise that was made when their partners do not keep their promises (Heyman, $\mathrm{Fu}$, Lin, Qian, \& Lee, 2015; Kanngiesser, Köymen, \& Tomasello, 2017). To our knowledge, all studies with children and adults investigating commitments focus on commitments made 
verbally. Therefore, our second aim was to investigate whether young children can understand even minimal nonverbal communicative signals as commitments to cooperate.

\section{Study 1}

In Study 1 we investigated to what extent a communicative, versus a non-communicative, look can produce an expectation of collaboration. While playing a novel version of the Stag Hunt game, 5-year-old children needed to decide whether to risk cooperating or take the safe option and play individually. At the critical moment, children saw that the cooperative option was available, but - unlike in the Wyman et al. (2013) study - they were not sure if the experimenter could see it as well. Thus, children were not able to assume common knowledge about the presence of the cooperative option. Immediately before children needed to make their decision, depending on the condition, the experimenter silently made either communicative or noncommunicative eye contact with them. We predicted that only communicative looks would establish common knowledge and promote cooperative decisions. We also investigated whether the communicative look could be seen by children as a commitment on the experimenter's part to collaborate. To do this, in both conditions the experimenter ended up playing for the individual option, and we gave children the chance to protest as a sign that they understood that their partner had broken a commitment to collaborate.

\subsection{Method}

\subsubsection{Participants}

Seventy-two 5-year-olds (36 girls, mean age: 5;2; range: $4 ; 11-5 ; 6)$ were included in the final sample. Additional children began testing but did not complete the training due to language difficulties (2) or failing the pre-tests (11). Other children were tested but excluded from analyses for not seeing the manipulation (5), disobeying instructions and communicating their decision to 
the experimenter (13), apparatus failure (3), or experimenter error (10). We recognize that this drop-out rate is higher than usual, and we attribute this to the complexity of the procedure and children's difficulty at inhibiting communication with the experimenter during the response phase (for more justification about why excluding these children was necessary, see below). Children's parents had given consent for them to participate in developmental studies. They were tested individually in their kindergartens in [blinded for review]. The university's ethics committee approved the study.

\subsubsection{Materials and design}

The apparatus for the game consisted of four tubes mounted at a downward angle towards a platform with boxes on it (see Figure 1). Two white tubes led to two white paper boxes representing the small prizes (i.e., the 'hares', the safe, individual option). Two colorful tubes led to one colorful wooden box representing the big prize (i.e., the 'stag', the risky, collaborative option). Children's partner was played by a puppet (controlled by an experimenter [E1]), because previous studies have shown that children are more likely to protest about the misbehavior of a puppet than that of an adult (e.g., Rakoczy et al., 2008). Behind the boxes sat another experimenter (E2) who operated the platform with boxes. The white boxes were always available, and the colorful box only occasionally also appeared in the middle. Children and the puppet could win the prizes by putting a marble into one of their two tubes, such that it rolled down the tube and knocked down the prize. There were small pegs in the tubes to prevent the marbles from rolling down the tubes until E2 gave permission for them to be released. Paper pictures of birds $(3 \times 3 \mathrm{~cm})$ were used as the small prizes and, during training, nice stickers $(3 \times 3$ $\mathrm{cm})$ were used as the big prizes. Before the test phase, these nice stickers were replaced with 'special' stickers $(4 \times 4 \mathrm{~cm})$ as the big prizes. Between children and the puppet there was a low 
barrier, so neither could see what the other chose, but they could both see each other's face. Another small occluder partially blocked the puppet's view of the colorful box, thus leaving children uncertain about the puppet's knowledge regarding the appearance of the big prize.

Figure 1. The apparatus with four tubes, two small prizes (the white boxes), one big prize (the colorful box), a partial occluder in front of the big prize on the puppet's side, and a barrier between the puppet and the child.

\subsubsection{Procedure}

Training: First, children played an unrelated warm-up game, to make them comfortable

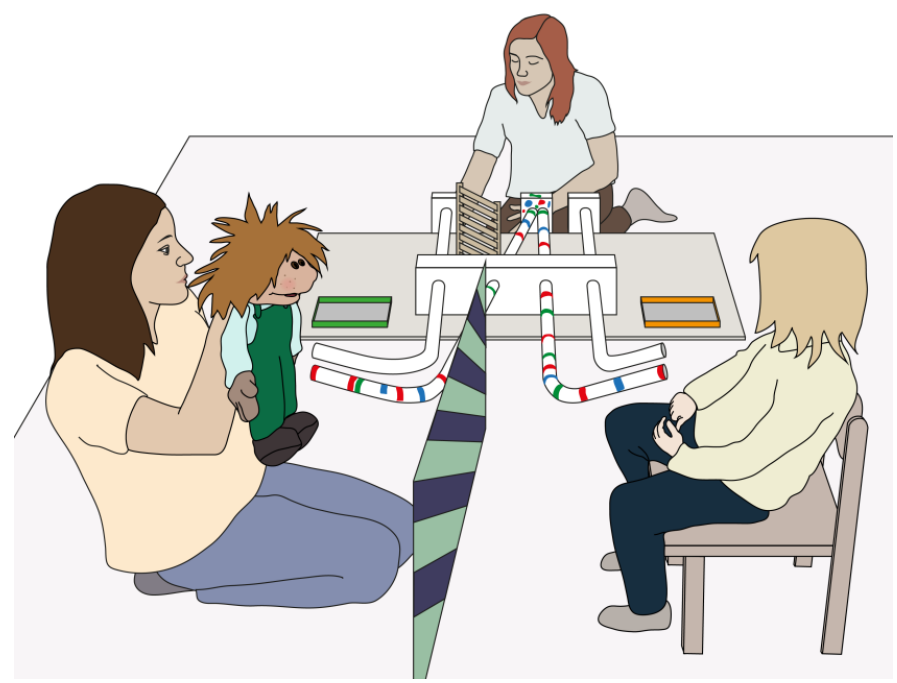

interacting with the puppet and correcting her when she made mistakes (see the Supplementary Material for further details of the procedure). Then E2 introduced the game to children and the puppet. They learned that they could decide to play either individually (for the white box), and be certain of winning a small prize, or, when a big prize was available, play cooperatively (for the colorful box) and have the possibility of winning a big prize if they both decided to cooperate (since it was too heavy for a single marble to knock down alone). It was established that children 
and the puppet had to decide quickly, otherwise the boxes would disappear. E2 explained that sometimes the big prize would appear, but because of the occluder, the puppet could not always see it.

At the beginning of each trial, E2 lifted the platform with boxes up so both partners could see them. Then E2 gave one marble to the child and one to the puppet, and, during training only, they verbally communicated to decide how to play. To learn the structure of the game, children received a series of individual and cooperative trials and two pre-tests. The first pre-test ensured that children understood that cooperation was needed to get the big prize. The second ensured that children were motivated to cooperate when the puppet was likely to cooperate. At the end of the training phase, E2 introduced a no-talking rule to prevent children from verbal communication about their decisions.

Test phase: There was just one test trial. Children and the puppet watched while the platform with both the small and the big prizes on it appeared. Children could see the big prize but were not sure if the puppet could see it too. The puppet turned so she was facing children and, because E1's eyes were more expressive than the puppet's, E1 performed two looking sequences with her face next to and moving in tandem with that of the puppet. To be included in the analyses, children had to make eye contact with E1 at least once during the manipulation.

In the communicative look condition, E1 made eye contact with children with an ostensive-communicative look: She opened her eyes widely and raised her eyebrows (see Figure 2a). This look potentially communicated the message, "I can see the big prize, let's cooperate," thus establishing common knowledge about the availability of the cooperative option. Then E1 looked back to the prizes. E2 gave a marble to each of them, and looked down. E1 repeated the communicative look, looked down to the openings of the tubes ambiguously (so children could 
not use her gaze direction to figure out how she would play), and the puppet put her marble into a tube, out of sight of children.

In the non-communicative look condition, each of the two looking sequences was split into two parts, with two shorter looks instead of one long one, since longer looks were judged as communicative by adults during informal piloting. After the prizes appeared, E1 (with a neutral, relaxed face) slowly turned her head in the direction of the child, made non-communicative eye contact with the child (i.e., neutrally, without raised eyebrows; see Figure 2b), and then continued on, looking past children's eyes and slightly to the side (approximately $30 \mathrm{~cm}$ from children's eyes). E1 then followed a similar path back to looking at the prizes, making eye contact a second time while doing so. After taking the marble, E1 repeated the same gaze path, but after passing children's eyes at the end, E1 looked just slightly to the side (approximately 10 cm from children's eyes). Then E1 looked down and the puppet played exactly as in the other condition. We included the looks to the side to make the eye contact seem less communicative. ${ }^{1}$ Children then needed to decide whether to play individually or cooperatively. In both conditions the puppet played for the individual option. Then E2 informed children that they were allowed to talk again and they could remove the pegs to release the marbles. At this point, E1 went back to holding the puppet in front of her face so that anything children said next would be directed to the puppet. Children who played individually received the small prize, and went directly to the questioning phase (see below). Children who played for the big prize saw that their marble did not knock down the big prize and that the puppet, who had played individually,

\footnotetext{
${ }^{1}$ We noticed, belatedly, that, following a holiday break in testing, there were some errors in E1's looks: In the communicative look condition, she began smiling slightly and in the non-communicative look condition she sometimes neglected to look away to the side after looking at children's eyes. It was necessary to drop these children because different information was provided to them, and the non-communicative looks seemed more communicative. We assessed interrater reliability on this coding decision by having an independent, naive coder code ten cases that the authors determined to be experimenter errors and ten other, randomly-selected cases in matching conditions. There was good agreement (Cohen's $\kappa=0.75$ ), and the few disagreements between the naive coder and the authors about the drop outs were resolved by discussion.
} 
knocked down the small prize. The puppet and E2 then provided increasingly specific cues to elicit a response from children. First, E2 said, "Oh," in a slightly surprised way. After 10 s, E2 asked, "What happened?", alternating gaze between children and the puppet. After 10 more s, the puppet said, "You, [child's name], tried to knock down the colorful box, but I knocked down the white box." After 10 more s, the puppet asked, “And what do you say about this?" E2 gave children an additional $10 \mathrm{~s}$ to respond, and then the puppet excused herself and left the room. Questioning phase and debriefing: To gain more insight into children's thinking, we asked children several exploratory questions about, for example, their expectations and feelings for the puppet (see the Supplementary Material for these questions and results). Then E2 told children that they had played well and gave them the special sticker from the test trial. E1 apologized for playing incorrectly, and thanked children for playing. 
a)

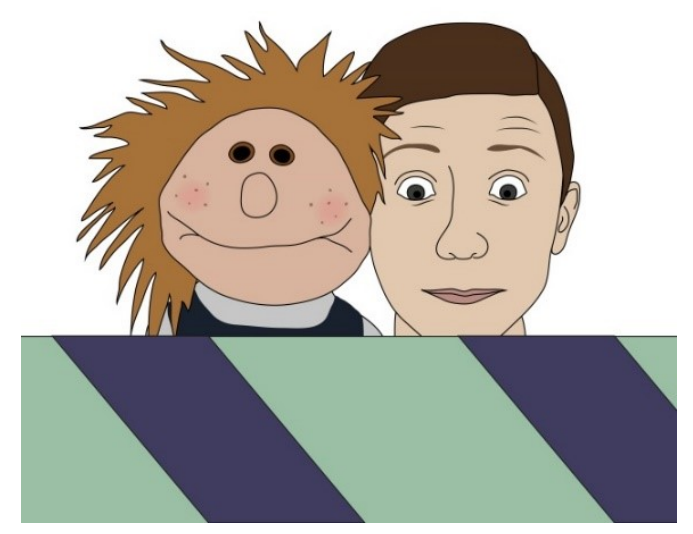

b)

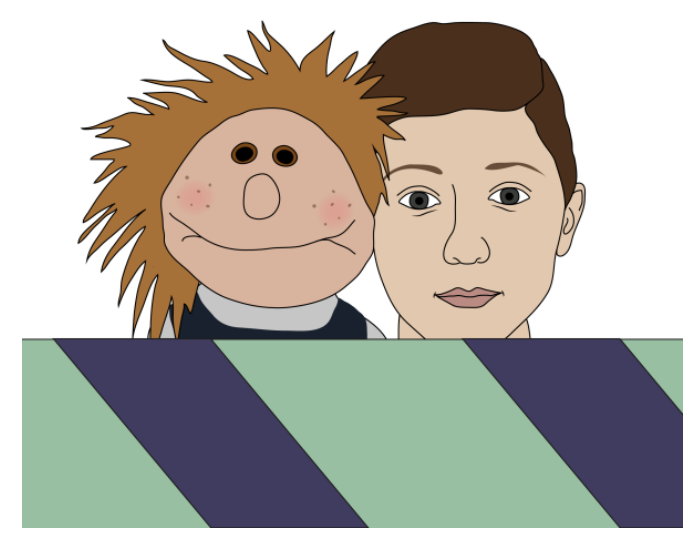

Figure 2. A depiction of a) the communicative look and b) the non-communicative look.

\subsubsection{Coding and reliability}

Sessions were videotaped. The main coding was done from the video-recordings by the first author. To assess inter-rater reliability, an independent coder who was naive to the hypotheses coded a random sample of $25 \%$ of the children in each condition. The data associated with this article are available from the Harvard Dataverse repository.

Cooperation vs. individual play: The main measure was whether children decided to cooperate. During the test trial, children's behavior was coded as either cooperation (if they put their marble into the colorful tube leading to the big prize) or individual play (if they put their marble into the white tube leading to the small prize). There was perfect inter-rater agreement on this measure.

Normative protest: We predicted that if children understood the communicative look as a commitment to cooperate, then they should protest more in the communicative look condition than in the non-communicative look condition. However, it was important to ensure that if this 
were the case, it was not simply because children were less successful (and thus more upset) in the communicative look condition, i.e., because they decided to cooperate more in this condition and so did not receive a prize. Thus for this and the subsequent measures exploring children's responses to their partner's decision to play individually, all responses from the test phase were transcribed and coded only for the subset of children in both conditions who had decided to cooperate. In that way, children's decision, and, importantly, their experience of not receiving a prize, were identical. Normative protest was coded when children used normative vocabulary (e.g., "should," "must," "wrong") while referring to how the puppet played; for example, "You should knock down the colorful box!” There was perfect inter-rater agreement.

Children's verbal responses to their partner's decision to play individually: To further examine how strong children's expectation was that their partner would cooperate, for the subset of children who decided to cooperate, along with normative protests, verbal utterances during the test phase were additionally coded for the following exhaustive but non-exclusive responses: (a) Explicit expectation of cooperation: children said they expected that the puppet would play for the big prize, for example, "I thought that you knocked down the colorful one." (b) Negative evaluation of the puppet: Children expressed frustration directed to the puppet, for example, "I think this is a little stupid." (c) Other: Children did not produce a response falling into either of the above categories (e.g., stayed silent or just described what happened). There was perfect inter-rater agreement.

Children's nonverbal responses to their partner's decision to play individually: In addition to verbal statements indicating that children had expected the puppet to collaborate, for the same subset of children we also coded nonverbal signs of this: displacement behaviors, disappointment, and/or anger during the response period. Behaviors were mutually exclusive and 
the exact frequency for each behavior that occurred during the response period was recorded. We predicted that if children had stronger expectations about their partner's cooperation in the communicative look condition, they should show more nonverbal signs that their expectations were violated in this condition. We used the Ethological Coding System for Interviews to code displacement behaviors (e.g., touching face, scratching, licking lips; Troisi, 2002). Displacement behaviors are self-directed activities that occur in situations characterized by stress and/or social tension, and which correlate with self-reported anxiety and negative affect (Troisi, 2002). They are thus a useful measure of violation of social expectations. We also coded for signs of disappointment (e.g., frown, disappointed voice, slumped body posture) and anger (e.g., clenched lips, annoyed voice or look, angry body posture, e.g., hands-on-hips gesture or raising fist at the puppet; adapted from Cole, Zahn-Waxler, \& Smith, 1994). Reliability was excellent for the number of both displacement behaviors $\left(r_{s}=0.92\right.$, with no difference between coders, Wilcoxon signed rank test: $p=0.31)$ and expressions of disappointment $\left(r_{s}=0.83\right.$, with no difference between coders, Wilcoxon signed rank test: $p=1$ ). No reliability coding for anger was conducted because only one such behavior was coded, and therefore anger was not included in the analysis. For statistical analyses, a composite score for nonverbal signs of violation of expectation of cooperation was calculated by summing the number of displacement and disappointment behaviors together (each behavior was equally-weighted).

Children's contribution to the mutual look in the communicative look condition: We also studied children's own contributions to the communicative look by investigating whether children contributed to the mutual gaze with a communicative behavior of their own. If so, by doing this, children would explicitly acknowledge their partner's commitment and/or even make a commitment back to her, thereby creating a joint commitment. We predicted that children who 
responded to their partner's communicative looks in this way would be even more likely to protest than children who did not. Children's reactions to the communicative look were coded as: raising their eyebrows, nodding (after receiving the look from E1), or no communicative behaviors. There was perfect inter-rater agreement on this measure. For the analyses, a binary outcome variable - whether or not each child produced a communicative behavior - was used.

\subsection{Results}

Cooperation vs. individual play: Children in the communicative look condition overwhelmingly decided for cooperation: $78 \%$ of them played cooperatively ( 28 children cooperated, 8 played individually, binomial probability, $\mathrm{p}=0.001)$. In contrast, in the noncommunicative look condition, only $47 \%$ of children played cooperatively (17 children cooperated, 19 played individually). Children in the communicative look condition cooperated significantly more often than children in the non-communicative look condition (Fisher's exact test, $p=0.01$; odds ratio $=3.83$ ).

Protests and other responses to the partner's decision to play individually: Only one child in each condition normatively protested after finding out that the puppet did not cooperate. Similarly, only a few children verbally expressed expectations of cooperation and/or negative evaluations of the puppet (see Table 1), thus no analyses were performed on these measures. However, for nonverbal signs of violation of expectation, there was a significant effect of condition: Children showed more nonverbal signs of violation of expectation in the communicative look condition $(M=3.75$, range $=0-10, S D=2.50)$ than in the non-communicative look condition $(M=1.65$, range $=0-4, S D=1.54$, Welch's $t$-test: $t=3.29, d f=40$, $\left.p=0.002, n_{1}=28, n_{2}=17\right)$. 
Children's contribution to the mutual look in the communicative look condition: Twentyfive percent of children in the communicative look condition showed some communicative signs ( 8 children raised their eyebrows and 1 raised the eyebrows and nodded) during the mutual look. As only one child normatively protested, no analyses were performed to investigate whether children who responded with communicative behaviors to E1 were more likely to protest than children who did not. The one child who protested did raise his eyebrows during the look.

Table 1

Percentage of Children who Showed the Different Verbal Response Types During the Test Phase in Study 1.

\begin{tabular}{lcc}
\hline \multicolumn{1}{c}{ Response types } & $\begin{array}{c}\text { Communicative look } \\
\text { condition }\end{array}$ & $\begin{array}{c}\text { Non-communicative } \\
\text { look condition }\end{array}$ \\
\hline Normative protests & $4 \%$ & $6 \%$ \\
Explicit expectations of cooperation & $14 \%$ & $0 \%$ \\
Negative evaluations of the puppet & $14 \%$ & $12 \%$ \\
Other & $71 \%$ & $88 \%$ \\
\hline
\end{tabular}

Note: Only the subset of children who played cooperatively are included ( $\mathrm{N}=28$ in the communicative look condition, $\mathrm{N}=17$ in the non-communicative look condition).

\subsection{Discussion}

At the crucial moment in a coordination game, when children needed to decide whether to play cooperatively or individually, the type of eye contact children's partner made with them influenced the inferences they made about their partner's likely behavior. The main finding was 
that children chose to cooperate more often when their partner looked at them with a communicative, compared to a non-communicative, look. When deciding whether to risk cooperating, children had to consider two important pieces of information: first, whether their partner had seen that the cooperative option was available and, second, whether she would then decide to cooperate. Therefore, children could interpret her ostensive-communicative look as a signal that she had seen the cooperative option and/or as a signal that she was going to cooperate. It is difficult to distinguish between these two interpretations because both implicitly include each other. For example, it was enough for the partner to signal that she had seen the cooperative option, because both children and the puppet knew together that cooperation was better for both partners and thus it was reasonable to assume cooperation would follow as long as both partners knew together that the cooperative option was available.

In addition, we found that children in the communicative look condition showed more nonverbal signs of violation of expectation when their partner played individually than children in the non-communicative look condition. This suggests that, even when children did cooperate in the non-communicative look condition, they had weaker expectations about the likelihood of their partner's cooperation.

Around half of the children cooperated even in the non-communicative condition. This is comparable to the cooperation rate in the Wyman et al. (2013) study, in which $48 \%$ of children cooperated in a condition with no eye contact. Note that behavior in a coordination game is dependent on both the probability of getting the prizes and the values of both types of prizes. The big prize was appealing and children were highly motivated to play for it, thus they were likely to err on the side of false positives. The chance-level cooperation rates in this condition suggest that either children were not sure what the non-communicative look meant and simply guessed 
what to do or half the children assumed their partner would play individually and half cooperatively.

Counter to our expectations, we found almost no normative protests about the partner's decision to not cooperate. Although at first most of the children interpreted the communicative look correctly as a signal to cooperate, they then saw that the puppet played individually. This might have led them to reinterpret their initial understanding of the communicative look. That is, as children have a general expectation that adults are competent (e.g., Taylor, Cartwright, \& Bowden, 1991), and an adult was controlling the puppet, they might have concluded that they had mistakenly interpreted the meaning of the look, and, instead of blaming the puppet/adult, may have blamed themselves for the coordination's failure.

In this study we clearly demonstrated that after seeing the communicative look, children had a strong expectation that their partner would cooperate, and therefore decided to cooperate themselves. However, because children rarely protested in this, here we could not demonstrate that children understood the communicative look as a commitment on the looker's part to cooperate. We should note here that only the child who protested normatively in the communicative look condition referred implicitly to a communicated commitment: "But you said [child mimics the communicative look]. For sure you picked the wrong hole." This suggests that some children might understand the communicative look as a commitment to cooperate. In order to investigate this further, we conducted Study 2.

\section{Study 2}

Some theorists would argue that a look cannot serve as a promissory commitment, since it is not a conventional act (Hume, 1739-1740/1969; Rawls, 1955; Searle, 1969). However, if, as others argue, promising is not rooted in social convention (Gilbert, 2004; Owens, 2006; Scanlon, 
1998; Shiffrin, 2008), it is feasible that under certain circumstances a communicative look could be sufficient for establishing a commitment, as it involves the promiser intentionally communicating in such a way as to induce the recipient to rely on her (MacCormick \& Raz, 1972; Scanlon, 1998), and allows individuals to express readiness to commit under conditions of common knowledge (Gilbert, 1990, 2004, 2014). To inform this theoretical discussion, we attempted again to find evidence that commitments can be created nonverbally. We manipulated the type of look children's partner gave them at the critical decision-making point in a coordination game and we focused more precisely on children's protests when they learned that their partner did not cooperate.

We modified the procedure in several ways to make protesting more likely to occur. First, we tested slightly older children: 6- to 7-year-olds. During the transition between preschool and early school age, children become more sensitive to the contexts in which norms apply, and their explicit reasoning about social norms becomes more advanced (Riggs \& Young, 2016; Smith, Blake, \& Harris, 2013). Therefore, we reasoned that slightly older children might feel more confident about protesting when their partner did not cooperate. Second, to make it less likely that children would blame themselves for the breakdown in coordination, we made the game easier and got rid of the occluder (so children were no longer uncertain about their partner's knowledge). Third, for children's partner we did not use a puppet, but rather an adult experimenter. To reduce children's inhibition about protesting towards adults, in a training phase, in both conditions, we encouraged children to protest when she behaved incorrectly. Finally, we made the cooperative option both more appealing and always available, so children in both conditions had a reason to expect cooperation and to cooperate. We did this because the rate of normative protesting in studies with young children is generally low, so to be able to detect any 
differences between conditions, we needed more children to cooperate (in order to have a chance to protest) in both conditions. Thus our aim in this study was not to measure children's cooperation rates and replicate Study 1; rather, it was to see whether children who cooperated would protest more following a communicative look than a non-communicative look. We conservatively focused on just one specific type of protest: normative protest referring, directly or indirectly, to the commitment (e.g., "You should have cooperated, because you told me you would"). We predicted that children in the communicative look condition would produce more of this specific type of protest than children in the non-communicative look condition. In addition, to zero in even more precisely on the role of the communicative look, children were only able to see the eye area of their partner during the critical decision-making phase: At this point, the two partners looked at each other through a tube.

\subsection{Method}

\subsubsection{Participants}

Seventy-two 6- to 7-year-olds (36 girls, mean age: 6;11; range: 6;4-7;3) were included in the final sample. We focused on children's protests about their partner's failure to cooperate; therefore, the final sample in both conditions was planned in advance to include only children who decided to cooperate and who thus had a reason to protest. Consequently, additional 15 children who played individually were excluded for this reason ( 8 in the non-communicative look and 7 in the communicative look condition). Additional children were tested but not included in the analyses for refusing to play the game (1), language comprehension difficulties (1), failing the second pre-test (2), and verbally or gesturally telling the experimenter how they would play during the critical decision-making phase (8). Participant recruitment was the same as in Study 1, except that children were tested in their schools. 


\subsubsection{Materials}

The materials for the main game included a blue rectangular rug $(170 \times 140 \times 170 \mathrm{~cm})$ decorated with fish representing a lake, and two low, yellow platforms decorated with palm trees representing the beach (see Figure 3). On the rug, there was a treasure box $(20 \times 26 \mathrm{~cm})$ containing seven small containers. Inside each container were the big prizes: two different stickers of animals $(4 \times 4 \mathrm{~cm})$. Between the two platforms, there was a tube $(13 \mathrm{~cm}$ diameter $)$

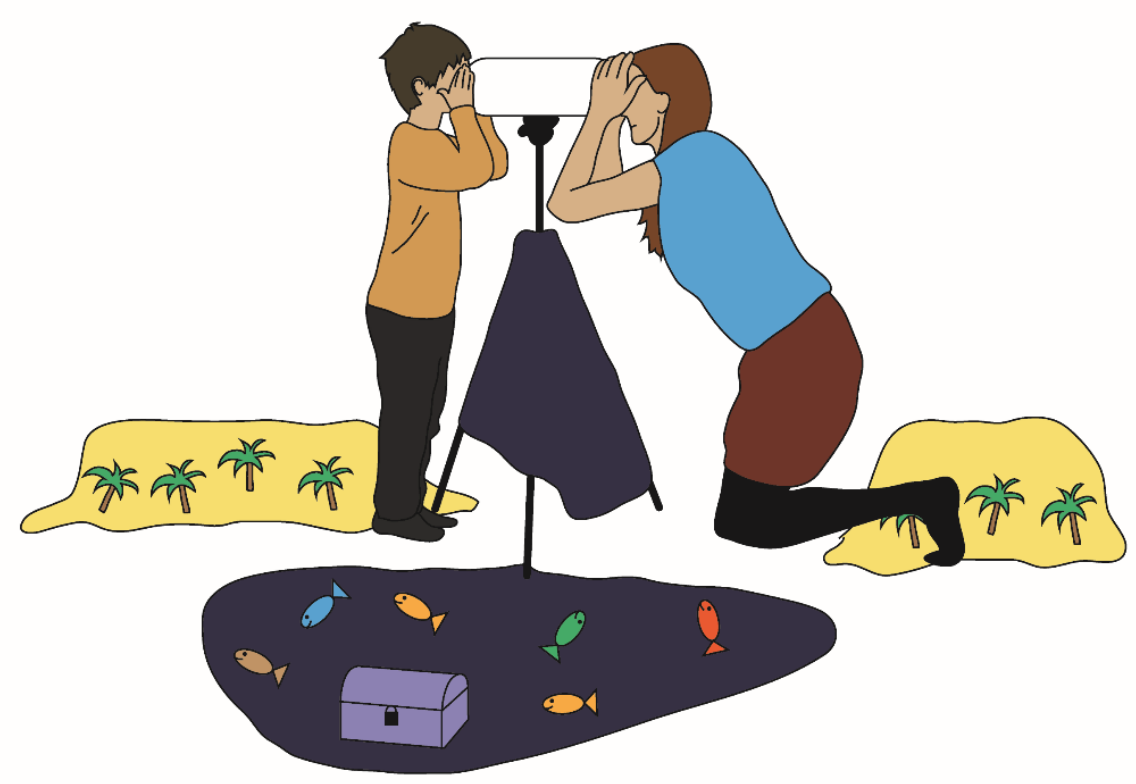

attached to a tripod with two spy cameras inside to film children's and their partner's face. Small paper pictures of a bird $(3 \times 3 \mathrm{~cm})$ were the small prizes.

Figure 3. The setup of Study 2: the tube, the lake representing the cooperative option, and the beach representing the individual option. 


\subsubsection{Procedure}

Training phase: Children began by playing a brief, unrelated warm-up game with their partner, E1. E1 sometimes made mistakes during this game and children were encouraged by E2 to correct her when this happened. E2 then introduced the main game and explained to children and E1 that they could decide to play individually (i.e., sit on the platform representing the beach) and be certain of winning a bird picture (small prize). Alternatively, they could decide to play cooperatively (i.e., jump onto the rug representing the lake) and have the possibility of winning a colorful sticker (big prize), as long as both of them did this together. They learned that at the beginning of each round, when deciding what to do, they had to look at each other through the tube, at which point E1 would verbally suggest where they should go. Then E1 would count to three and clap her hands as a signal for children to decide what to do. E1 always responded after children so they could not decide based on her decision. After three training trials, in which children learned the general structure of the game, E2 asked children two questions as a first pretest to see if they understood the structure of the payoffs. Then there was a series of 10 trials in the following order: individual, cooperative, mismatch, individual, cooperative, mismatch, mismatch, individual, cooperative, cooperative. In individual trials both E1 and children played individually, in cooperative trials both cooperated, and in the mismatch trials E1 suggested that she would cooperate, but after children played cooperatively, E1 played individually. If children did not say something about this spontaneously, E2 encouraged them to correct E1 and then E2 corrected E1 himself. These mismatch trials, together with the mismatch trials in the warm-up game, served as a second pre-test to ensure that children were not too shy to protest. To continue to the test, children needed to correct E1 spontaneously at least once in each game. Please see the Supplementary Material for further details. 
Test: The test consisted of three phases, as follows.

Decision-making phase: After the training phase, E2 introduced a no-talking rule, telling children and E1 that from now on they were not allowed to talk while looking through the tube, although they could talk again after having jumped or sat on the beach. Then E2 moved away to write something down and E1 looked through the tube in such a way that children could see only her eye area. Although children could not see it, the corners of E1's mouth were turned slightly upward to express a generally positive attitude in both conditions. In the non-communicative look condition, E1 made neutral eye contact with children for a few seconds. In the communicative look condition, E1 made eye contact with children with an ostensivecommunicative look: She opened her eyes wide and raised her eyebrows (see Figure 4). After the look, E1 returned to an upright position, counted to three, clapped her hands, and waited for children to make their decision, all the while with her gaze still directed neutrally toward the tube. After children had decided, in both conditions E1 played individually. If children played individually, E2 gave them the small prize, and the test phase ended.

a)

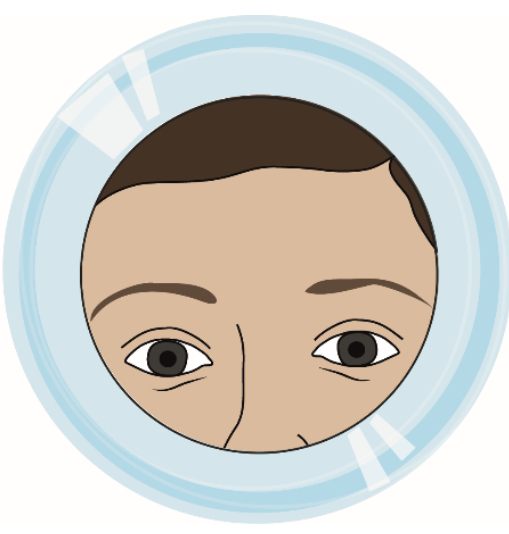

b)

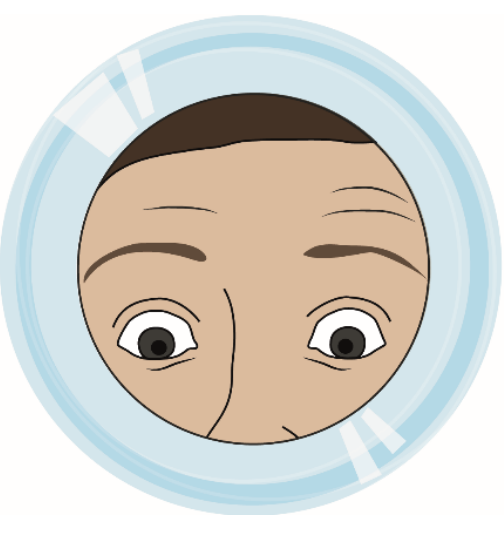

c)

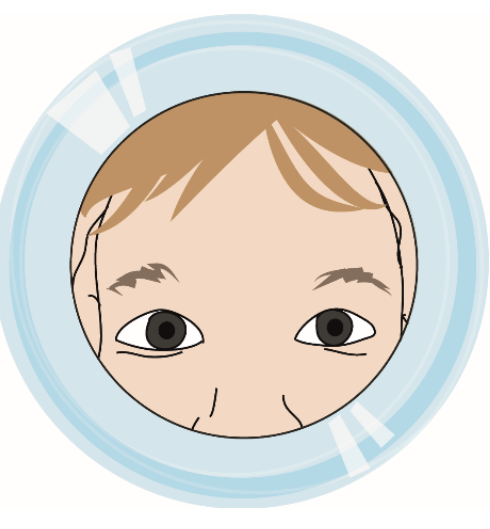


Figure 4. A depiction of a) the non-communicative look, b) the communicative look, and c) the child's face position.

Spontaneous response phase. If children played cooperatively, they then had $30 \mathrm{~s}$ to talk spontaneously to E1. E1 sat silently on the platform and looked at children with a slightly positive expression.

Elicited response phase:

After 30 s, E2 returned and asked children five questions.

1. "What happened, [child's name]? Tell me."

2. "Did [E1] perhaps give you any sign that she would jump?" If children responded yes, E2 asked: "What sign did she give you?"

3. "Do you want to say something about that to [E1]? Tell her what you think about what she just did. I'm sure she would be glad to know.” E1 nodded.

Then E1 excused herself, left the room, and E2 continued:

4. "Do you remember when you jumped to the lake and [E1] did not? What did you expect her to do?"

5. "Why did you expect that [E1] would jump to the lake/stay at the beach?"

Debriefing: Then E1 returned and apologized for playing incorrectly. They played two successful cooperative trials together, after which children were thanked and taken back to class.

\subsubsection{Coding and reliability}

Sessions were videotaped and coded from the video recordings by the first author. A second independent observer, who was naive to the hypotheses of the study, coded a random sample of $25 \%$ of children in each condition for reliability. There was perfect agreement on all 
measures.

Cooperation vs. individual play: During the test trial, children's behavior was coded either as cooperation, if they jumped onto the rug representing the lake, or as individual play, if they sat on the platform representing the beach. This was coded because we only included children who cooperated.

Children's spontaneous protest after their partner did not cooperate: Children's verbal responses during the spontaneous response phase were transcribed, and we coded for protests that indicated that children understood E1's look as a commitment to cooperate. Promissory commitments can arise when there is intentional communication to one's partner about one's intention to perform some action (Raz, 1977). We did not expect these young children to refer explicitly to commitments; instead, we focused on protests that involved what E1 had communicated that she would do. We decided to focus on this specific type of protest because we had found that in Study 1 the child who protested normatively in the communicative look condition referred implicitly to a communicated commitment. This decision was made before the data collection began. Normative protest referring, directly or indirectly, to the commitment was coded when children used normative vocabulary (e.g., "should," "must," "wrong") and mentioned communication of any type (including verbal, gestural, with the eyes/looks, or with facial expressions, e.g., "You should do what you said!” or "[E1], that was wrong. You should pay attention to your sign." This enabled us to focus on the commitment part of the protest, disentangling it from children's general disappointment about the fact that their partner did not cooperate (e.g., "You should have cooperated, because I wanted the sticker"). For exploratory purposes, children's spontaneous responses were coded in a more fine-grained manner as well; see the Supplementary Material for details. 
Children's protest across the entire response phase: Children's verbal responses across the entire response phase (i.e., the spontaneous plus the elicited response phase) were also transcribed and coded for normative protest referring, directly or indirectly, to the commitment. This was coded when the child used normative vocabulary and mentioned communication either together in one utterance (e.g., "One does not do that, that was wrong; you should do what you said") or separately across responses to different questions (e.g., if children said in the spontaneous response phase, "You did it wrong, I think," and later responded to one of the questions, "She did this (the child raised her eyebrows), so I did this (the child raised her eyebrows) and because of that I understood that she would stand over the treasure so with that I understood "to the lake."”

\section{Children's contribution to the mutual look in the communicative look condition: We} again investigated whether children who responded to their partner's communicative looks (thus explicitly acknowledging their partner's commitment and/or even making a joint commitment) were more likely to protest than children who did not. Children's reactions to the communicative look were coded as: raising their eyebrows, nodding (after receiving the look from E1), or no communicative behaviors. For the analyses, a binary outcome variable - whether or not each child produced a communicative behavior - was used.

\subsection{Results}

At test, more children in the communicative look condition produced normative protests referring to commitment than did children in the non-communicative look condition, both in the spontaneous phase alone (marginally; Fisher's exact test, $p=0.06$; odds ratio $=3.13$ ) and when their responses across the entire response phase were considered (Fisher's exact test, $p=0.01$; odds ratio $=4.38$ ). In the communicative look condition, $39 \%$ of children protested spontaneously 
and $47 \%$ protested at least once across the entire response phase. In contrast, in the noncommunicative look condition, $17 \%$ of children protested, both in the spontaneous part and across the entire response phase.

Children who responded with communicative behaviors to E1 tended to be more likely to protest than children who did not (Fisher's exact test, $p=0.08$; odds ratio $=4.20)$. Forty-seven percent of children in the communicative look condition showed some communicative behaviors (see Table 2). Of these children, $69 \%$ protested. In contrast, of the children who did not show any such behaviors, only $33 \%$ protested.

Table 2

Children's Communicative Behaviors During the Mutual Look in the Communicative Look Condition and Their Relation to Children's Protesting in Study 2.

Normative protests referring to commitment
No normative protests referring to commitment
Communicative behaviors

Raised eyebrows

Nodding

Raised eyebrows and nodding

No communicative behaviors
11

10

1

0

6
5

4

0

1

12

Note: $\mathrm{N}=34$. Due to a technical error, four videos were missing. E1 noticed the technical failure in two cases and noted live whether children showed any communicative behavior or not. These two cases are included in the table. 


\subsection{Discussion}

At the moment of decision-making, children's partner engaged in communicative or noncommunicative eye contact with them and subsequently did not cooperate. Children who received a communicative look were more likely to protest about this, referring specifically to their partner's commitment, than children who received a non-communicative look. The vast majority of these children referred explicitly to "doing what you said [you would do]," but three children referred to nonverbal signs E1 had given (e.g., a certain kind of look). This suggests that children understood the communicative look as a binding statement from their partner in which she committed herself to choosing the cooperative option in the game.

It is interesting to note that approximately half of the children responded to E1's communicative look with looks (or other communicative behavior) of their own. One possible low-level interpretation of this behavior is that children automatically mimicked E1's communicative look. A second, more plausible interpretation is that children intentionally sent a communicative message back to E1. Two pieces of evidence support the latter interpretation. First, some children mentioned their own responses in their answers to E2's questions, (e.g., "She [E1] did this [the child raised her eyebrows], so I did this [the child raised her eyebrows] so I understood...”). Second, the results showed that children who produced these nonverbal signs themselves tended to be more likely to protest. It is likely that these signs served at least to acknowledge the partner's commitment to cooperate and, perhaps, in addition, to commit children themselves to cooperating too, thus forming a joint commitment. Either way, however, their partner did not fulfill her commitment, and thus children were entitled to protest. 


\section{General Discussion}

When deciding whether or not to cooperate, we are often faced with two challenges: uncertainty about our partner's knowledge and uncertainty about their future behavior. Here we investigated one key nonverbal way of overcoming these challenges. Children who received a communicative, as compared to a non-communicative, look when deciding whether to cooperate both cooperated more (Study 1) and normatively protested more when their partner did not cooperate (Study 2). Thus, a communicative look can be powerful enough not only to promote expectations of cooperation but also to signal a commitment. This is the first empirical evidence, in adults or children, suggesting that nonverbal signals can be understood as commitments.

In Study 1, we focused on the uncertainty we may have about our partner's knowledge (in this case about the availability of the cooperative option). We demonstrated that the type of eye contact made influenced children's decisions to cooperate. Wyman et al. (2013) had previously shown that a communicative look increased young children's cooperation as well. However, our study goes beyond theirs in isolating precisely what it is that established common knowledge about the cooperative option and led children to cooperate: the communicativeness of the look. Intentionally communicative eye contact not only transmits information from one social partner to another, but also provides an indication of where each partner's attention is focused, and thus removes any doubt about whether the partners are paying attention to the same thing and to each other (Carpenter \& Liebal, 2011; Gómez, 1994). It thus creates a public space between the partners, enabling them to focus on something together (Gilbert, 2007).

Therefore, here we add a new type of information that children can use to solve the knowledge problem in coordination problems. Previous studies have shown that 5-year-old children are able to solve different coordination problems by using salience (Grüeneisen, 
Wyman, \& Tomasello, 2015a), majority information (Grüeneisen, Wyman, \& Tomasello, 2015b), and their partners' cultural knowledge (Goldvicht-Bacon \& Diesendruck, 2016). Study 1 extends these findings by focusing on interpersonal signals that children can use in solving coordination problems.

In Study 2, we focused on the second challenge for successful cooperation involving uncertainty about one's partner's behavior. We found that after receiving a communicative look, children understood that their partner was committing herself to cooperate. Previous studies have all involved children's understanding of verbal promises and commitments (Gräfenhain et al., 2009; Kachel et al., 2017; Kanngiesser et al., 2017). Here we showed that a nonverbal communicative signal can be understood as a commitment as well. Thus, along with contributing to the psychological literature by demonstrating that young children can normatively evaluate a nonverbal communicative signal as a binding statement, we also contribute to the theoretical debate in the philosophical literature, by showing that it is indeed possible to make a promissory commitment nonverbally. Even though a communicative look is not a conventionalized way of committing oneself, children still protested normatively and referred to a commitment (e.g., mentioning 'doing what you said you would do') after their partner looked at them communicatively but did not cooperate. This finding supports the more contemporary accounts of promissory obligations (Gilbert, 2004; Owens, 2006; Scanlon, 1998; Shiffrin, 2008) that argue that the core of promissory commitments might not be rooted in social convention (as Hume, 1739-1740/1969, Rawls, 1955, \& Searle, 1969, have proposed).

One might wonder whether the communicative look signaled a promissory commitment in the strict sense, with normative obligations and rights involved, or rather only a more minimal 'sense of commitment' (Michael, Sebanz, \& Knoblich, 2015). We argue for the former 
interpretation. All the children in Study 2 had decided to cooperate and in both conditions $75 \%$ of children answered to a post-test question that they had expected cooperation from their partner. This shows that children in the non-communicative look condition had explicit expectations about cooperation as well. However, after receiving a communicative look, around half of the children not only felt that they had the right to protest against their partner when she did not cooperate, but also often referred specifically in their protests to what she had said she would do. One might argue that children still did not understand their partner's nonverbal message as a binding statement committing her to cooperate. However, it does not seem plausible that intentional communication in this context can be perceived as an informative but non-binding statement at the same time (e.g., "I will cooperate, but I do not promise").

The communicative look could signal a commitment because children and their partner had the common ground that during the decision-making phase they were deciding whether to cooperate. This common ground supported their interpretation of the look. The most relevant and the only missing piece of - information when children saw the look was about whether E1 had seen the cooperative option (Study 1) or whether she was going to cooperate (Study 1 and 2). In fact, the difference in context and the most relevant information in the situation could explain why children apparently interpreted the communicative look differently in the two studies. In Study 1, children and their partner already had common ground about the payoff structure of the game: They knew together that the cooperative option had a higher payoff, but that it was risky, because if one partner decided for cooperation alone, she would lose the chance to gain anything. However, there was uncertainty created by the partial occluder about whether the partner could see the cooperative option or not. Children might thus have interpreted the communicative look as "I see it!", which then led them to expect cooperation but not necessarily to hold their partner 
normatively responsible for not cooperating. In contrast, in Study 2, children and their partner not only had common ground about the payoff structure but also about the availability of the cooperative option, so the most relevant information during the decision-making phase was about the decision to cooperate or not. Therefore, children likely interpreted the look as directly related to deciding whether to cooperate and the communicative look could signal a commitment. This might be one main reason why children protested only in Study 2, not in Study 1.

There are likely several other reasons why children protested in Study 2, and not in Study 1. First, in Study 2 there were several training rounds to ensure that children were not too shy to protest to an adult experimenter about her behavior. Thus, it is possible that in Study 2 children felt more confident about blaming their partner for the coordination's failure. Second, in Study 2 we tested older children (6- to 7-year-olds) than in Study 1 (5-year-olds). Thus, children's developing understanding of social norms (see, e.g., Smith et al., 2013) might have contributed to our findings. Even 3-year-olds protest when their partner intentionally performs a task incorrectly (Kachel et al., 2017) or violates simple game rules (Rakoczy et al., 2008), but in our studies children faced an arguably much more challenging task. In a Stag Hunt game, the fact that the partner played individually is not in itself an incorrect or wrong action, so children could not refer to any rule of the game in their protests. Instead, what was wrong was that their partner intentionally made children believe that she would cooperate, but then did not follow through. As she did all this nonverbally, it might be that only older children could formulate this in their protests. The relation between children's developing understanding of norms and nonverbal commitments, as well as the question of whether even younger children also understand nonverbal commitments, are two important questions for future research. Even infants can infer 
some types of information from ostensive-communicative eye contact (Csibra \& Gergely, 2006; Senju \& Csibra, 2008), but we would only expect children to show the same pattern of protest results once they have reached an age at which they understand something about norms and commitments, around 3 years of age (Gräfenhain et al., 2009; Rakoczy et al., 2008).

It is interesting to note that looks do not have the specificity that language has, but this is not a problem here, because the certainty connected to a specific meaning just needs to be sufficient for the current purposes (Monderer \& Samet, 1989). It is an open question in this regard whether nonverbal signals can fulfill all the same functions in creating expectations and signaling commitments as verbal signals, or whether under certain conditions (e.g., when the risk is too high, for example risking one's life), we might hesitate to rely on nonverbal signals. Future research should manipulate the risk-to-reward ratio to investigate this. Similarly, it would be interesting to compare the effectiveness of increasingly specific nonverbal signals (from just looking to smiling and/or winking and/or pointing and/or nodding) in promoting coordination success and creating commitments, and to study this cross-culturally to see if children in different cultures vary in their normative understanding of communicative signals with various degrees of explicitness.

In summary, these studies are the first to show that the subtle, nonverbal cue of a communicative look - but not a non-communicative look - can be a powerful tool for increasing coordination success in social dilemmas. In the context of a key coordination dilemma, communicative looks at the critical decision-making phase produced an expectation of collaboration in 5-year-old children, and 6- to 7-year-old children apparently even understood the communicative looks as a commitment to cooperate. The ability to produce communicative looks, infer their meaning, and make commitments nonverbally might have been important steps 
Communicative eye contact signals a commitment 36

in the evolution of action coordination in humans. These skills would have enabled successful coordination even before language evolved. 


\section{Acknowledgments}

We would like to thank the children for their participation; Susanne Mauritz, Elena Rossi, Theo Toppe, Anna-Marie Seidel, Nathalie Dosch, and Rahel Doehring for help with data collection; Christina Juengst, Silvan Hornstein, and Felix Wenger for help with coding; Roger Mundry for statistical advice; and Margherita Isella, Cathal O'Madagain, and John Michael for inspiring discussions. We also thank three anonymous reviewers for their helpful comments.

This research did not receive any specific grant from funding agencies in the public, commercial, or not-for-profit sectors. 


\section{References}

[dataset] Data available from the Harvard Dataverse repository: Siposova, B., Tomasello, M., \& Carpenter, M. (2018). Dataset: Communicative eye contact signals a commitment to cooperate for young children, Harvard Dataverse (V4, 2018), https://doi.org/10.7910/DVN/Y3LADG, UNF:6:nZf4dwUPENyp2zi/Rt/rlQ==

Austin, J. L. (1975). How to do things with words. Cambridge, MA: Harvard University Press.

Brosnan, S. F., Wilson, B. J., \& Beran, M. J. (2012). Old world monkeys are more similar to humans than new world monkeys when playing a coordination game. Proceedings of the Royal Society of London B: Biological Sciences, 279(1733), 1522-1530. doi:10.1098/rspb.2011.1781

Brownell, C. A. (2011). Early developments in joint action. Review of Philosophy and Psychology, 2(2), 193-211. doi:10.1007/s13164-011-0056-1

Carpenter, M., \& Liebal, K. (2011). Joint attention, communication, and knowing together in infancy. In A. Seemann (Ed.), Joint attention: New developments in psychology, philosophy of mind, and social neuroscience (pp. 159-181). Cambridge, MA: MIT Press.

Chwe, M. (2001). Rational ritual: Culture, coordination, and common knowledge. Princeton, NJ: Princeton University Press.

Clark, H. H. (1996). Communities, commonalities, and communication. In J. Gumperz \& S. Levinson (Eds.), Rethinking linguistic relativity (pp. 324-355). Cambridge, England: Cambridge University Press. 
Cole, P. M., Zahn-Waxler, C., \& Smith, K. D. (1994). Expressive control during a disappointment: Variations related to preschoolers' behavior problems. Developmental Psychology, 30(6), 835-846. doi:10.1037/0012-1649.30.6.835

Csibra, G. \& Gergely, G. (2006). Social learning and social cognition: The case for pedagogy. In Y. Munakata, \& M. H. Johnson (Eds.), Processes of change in brain and cognitive development. Attention and performance, XXI. (pp. 249-274). Oxford, England: Oxford University Press.

Duguid, S., Wyman, E., Bullinger, A. F., Herfurth-Majstorovic, K., \& Tomasello, M. (2014). Coordination strategies of chimpanzees and human children in a Stag Hunt game. Proceedings of the Royal Society of London B: Biological Sciences, 281(1796), 20141973. doi:10.1098/rspb.2014.1973

Gilbert, M. (1990). Walking together: A paradigmatic social phenomenon. Midwest Studies In Philosophy, 15(1), 1-14. doi:10.1111/j.1475-4975.1990.tb00202.x

Gilbert, M. (2004). Scanlon on promissory obligation: The problem of promisees' rights. Journal of Philosophy, 101(2), 83-109. doi:10.5840/jphil200410126

Gilbert, M. (2007). Mutual recognition, common knowledge, and joint attention. In T. RønnowRasmussen, B. Petersson, J. Josefsson, \& D. Egonsson (Eds.), Hommage à Wlodek: Philosophical papers dedicated to Wlodek Rabinowicz (pp. 1-21).

Gilbert, M. (2014). Three dogmas about promising. In Joint commitment: How we make the social world. New York, NY: Oxford University Press.

Goldvicht-Bacon, E., \& Diesendruck, G. (2016). Children's capacity to use cultural focal points in coordination problems. Cognition, 149, 95-103. doi:10.1016/j.cognition.2015.12.016 
Gómez, J. C. (1994). Mutual awareness in primate communication: A Gricean approach. In S. Parker, R. Mitchell, \& M. Boccia (Eds.), Self-awareness in animals and humans: Developmental perspectives (pp. 61-80). Cambridge, England: Cambridge University Press. doi:10.1017/CBO9780511565526.007

Gómez, J. C. (1996). Ostensive behaviour in great apes: The role of eye contact. In A. Russon, K. Bard, \& S. Taylor Parker (Eds.), Reaching into thought: The mind of the great apes (pp.131-151). Cambridge, England: Cambridge University Press.

Gräfenhain, M., Behne, T., Carpenter, M., \& Tomasello, M. (2009). Young children’s understanding of joint commitments. Developmental Psychology, 45(5), 1430-1443. doi:10.1037/a0016122

Grüeneisen, S., Wyman, E., \& Tomasello, M. (2015a). Children use salience to solve coordination problems. Developmental Science, 18(3), 495-501. doi:10.1111/desc.12224

Grüeneisen, S., Wyman, E., \& Tomasello, M. (2015b). Conforming to coordinate: Children use majority information for peer coordination. British Journal of Developmental Psychology, 33(1), 136-147. doi:10.1111/bjdp.12078

Heyman, G. D., Fu, G., Lin, J., Qian, M. K., \& Lee, K. (2015). Eliciting promises from children reduces cheating. Journal of Experimental Child Psychology, 139, 242-248. doi:10.1016/j.jecp.2015.04.013

Hume, D. (1969). A treatise of human nature. London, England: Penguin. (Original work published 1739-1740).

Lewis, D. (1969). Convention: A philosophical study. Cambridge, MA: Harvard University Press. 
Kachel, U., Svetlova, M. \& Tomasello, M. (2017). Three-year-olds' reactions to a partner’s failure to perform her role in a joint commitment. Child Development. doi:10.1111/cdev.12816

Kanngiesser, P., Köymen, B., \& Tomasello, M. (2017). Young children mostly keep, and expect others to keep, their promises. Journal of Experimental Child Psychology, 159, 140-158. doi:10.1016/j.jecp.2017.02.004

Kolodny, N., \& Wallace, R. J. (2003). Promises and practices revisited. Philosophy \& Public Affairs, 31(2), 119-154. doi:10.1111/j.1088-4963.2003.00119.x

MacCormick, N., \& Raz, J. (1972). Voluntary obligations and normative powers. Proceedings of the Aristotelian Society, 46, 59-102. doi:10.1093/aristoteliansupp/46.1.59

Michael, J., \& Pacherie, E. (2015). On commitments and other uncertainty reduction tools in joint action. Journal of Social Ontology, 1(1), 89-120. doi:10.1515/jso-2014-0021

Michael, J., Sebanz, N., \& Knoblich, G. (2015). The sense of commitment: a minimal approach. Frontiers in Psychology, 6, 1-11. doi:10.3389/fpsyg.2015.01968

Monderer, D., \& Samet, D. (1989). Approximating common knowledge with common beliefs. Games and Economic Behavior, 1(2), 170-190. doi:10.1016/0899-8256(89)90017-1

Owens, D. (2006). A simple theory of promising. Philosophical Review, 115(1), 51-77. doi:10.1215/00318108-115-1-51

Rakoczy, H., Warneken, F., \& Tomasello, M. (2008). The sources of normativity: young children's awareness of the normative structure of games. Developmental Psychology, 44(3), 875. doi:10.1037/0012-1649.44.3.875

Rawls, J. (1955). Two concepts of rules. The Philosophical Review, 64(1), 3-32. doi: $10.2307 / 2182230$ 
Raz, J. (1977). Promises and obligations. In P. M. S.Hacker \& J. Raz, (Eds.), Law, morality, and society: essays in honour of HLA Hart. (pp. 210-228). Oxford, England: Clarendon Press.

Rousseau, J. (1984). A discourse on inequality. New York, NY: Penguin Books. (Original work published 1754)

Riggs, A. E., \& Young, A. G. (2016). Developmental changes in children's normative reasoning across learning contexts and collaborative roles. Developmental Psychology, 52(8), 12361246. doi:10.1037/dev0000119

Sally, D. (1995). Conversation and cooperation in social dilemmas a meta-analysis of experiments from 1958 to 1992. Rationality and Society, 7(1), 58-92.

Searle, J. R. (1969). Speech acts: An essay in the philosophy of language. Cambridge, England: Cambridge University Press.

Senju, A., \& Csibra, G. (2008). Gaze following in human infants depends on communicative signals. Current Biology, 18(9), 668-671. doi:10.1016/j.cub.2008.03.059

Scanlon, T. (1998). What we owe to each other. Cambridge, MA: Harvard University Press.

Shiffrin, S. (2008). Promising, conventionalism, and intimate relationships. Philosophical Review, 117(4), 481-524. doi:10.1215/00318108-2008-014

Siposova, B., \& Carpenter, M. (in prep.). A new look at joint attention and common knowledge. Manuscript in Preparation.

Skyrms, B. (2004). The stag hunt and the evolution of social structure. Cambridge, England: Cambridge University Press. doi:10.1017/CBO9781139165228

Smetana, J. G. \& Braeges, J. L. (1990). The development of toddlers' moral and conventional judgments. Merrill-Palmer Quarterly, 36(3), 329-346. 
Smith, C. E., Blake, P. R., \& Harris, P. L. (2013). I should but I won't: Why young children endorse norms of fair sharing but do not follow them. PLoS ONE, 8(3), 1-11. doi:10.1371/journal.pone.0059510

Sperber, D., \& Wilson, D. (1986). Relevance: Communication and cognition. Oxford, England: Basil Blackwell.

Tomasello, M. (2008). Origins of human communication. Cambridge, MA: MIT Press.

Thomas, K. A., DeScioli, P., Haque, O. S., \& Pinker, S. (2014). The psychology of coordination and common knowledge. Journal of Personality and Social Psychology, 107(4), 657-676. doi:10.1037/a0037037

Troisi, A. (2002). Displacement activities as a behavioral measure of stress in nonhuman primates and human subjects. Stress, 5(1), 47-54. doi:10.1080/102538902900012378

Vaish, A., Missana, M., \& Tomasello, M. (2011). Three-year-old children intervene in third-party moral transgressions. British Journal of Developmental Psychology, 29(1), 124-130. doi:10.1348/026151010x532888

Wyman, E., Rakoczy, H., \& Tomasello, M. (2013). Non-verbal communication enables children's coordination in a "Stag Hunt" game. European Journal of Developmental Psychology, 10(5), 597-610. doi:10.1080/17405629.2012.726469 
Communicative eye contact signals a commitment 44

7. Conflicts of interest:

None. 


\section{Supplementary Material}

\subsection{Study 1}

\subsubsection{Method}

\subsubsection{Procedure}

Training: Children were picked up from their classroom by E1, who introduced herself and the puppet. As they entered the testing room, E2 introduced herself and a small stuffed animal - a cat from a popular children's cartoon, and familiarized the child with a smiley scale that would be used at the end of the procedure. Then children played a warm-up game with the puppet. The puppet performed three actions incorrectly (e.g., wrote with the wrong end of a pen) and children were encouraged by E2 to correct her. E2 then explained the main game. She showed children and the puppet that they could win prizes by putting a marble into one of two tubes to knock down one of two boxes. E2 introduced the partial occluder, and the puppet said that sometimes she could see the big prize and sometimes not but that she could always see the small prize. During training, children received four types of trials: In the trials in which the puppet can see the big prize, she said, "Look, the colorful box! Let's play together, [child's name], so we can get a colorful sticker." In the trials in which she could not see the big prize, she said aloud to herself, "I can just see the white box. So I'll play alone to knock down the white box," and she put her marble in the tube for the white box quickly so she could not change her decision if children corrected her. In the only small prizes trials, the puppet said, "Look, [child's name], only white boxes." In a single child alone trial, the puppet excused herself for a moment, and children played the fourth trial alone. This trial served as a first pre-test to ensure that children understood that it was not possible to get the big prize alone. To pass this pre-test, they needed to play for the small prize, even though the big prize appeared as well. If children 
decided to play for the big prize, E2 explained the rules of the game again, started training from the beginning, and children were given one additional chance to pass this pre-test. The training trials were presented in the following order: puppet can see the big prize, puppet cannot see the big prize, only small prizes, child alone, only small prizes, puppet cannot see the big prize, puppet can see the big prize, only small prizes. Of these, together the puppet can and cannot see the big prize trials served as the second pre-test, ensuring that children were motivated to play for the big prize when the puppet was likely to play for it but did not play for it when the puppet could not see it. If children did not play appropriately in any given trial, additional feedback was provided, and the trial was repeated once. To pass this pre-test, children had to play appropriately on the first or second attempt of each of these types of trials. Children who failed any of the pretests played one more cooperative trial, received a special sticker, and were thanked for playing so nicely and escorted back to class. For children who passed the pre-tests, before the last training trial, E2 showed children and the puppet a new, special sticker that would serve as the next big prize. Then a no-talking rule was introduced: E2 pretended that the cat wanted to sleep and said, "From now on, we have to be very quiet, and you can't talk to each other anymore so [cat's name] can sleep. This is a very important rule, okay? But don't worry; you can still see each other's faces so you will still be able to keep playing." Then a final small prize trial was conducted in order to make sure children would follow the no-talking rule.

\subsubsection{Supplementary coding and results for the post-test questions}

For exploratory purposes, to gain more information about children's behaviors, we asked children a series of questions at the end of the procedure. Children's verbal responses and behaviors were transcribed from the video recordings and a second independent observer who was naive to the hypotheses of the study coded a random sample of $25 \%$ of the children in each 
condition. Reliability revealed excellent agreement for all measures (Cohen's $\kappa$ 's ranged from 0.90-1).

At the beginning of the interview phase, E2 asked the child, "How do you feel right now?" and she pointed to and asked about each choice on the 5-point smiley scale (ranging from 1 "Do you feel very sad?" to 5 "Do you feel very happy?"). With this question, we wanted to investigate differences in mood between conditions within the subset of children who cooperated. Stronger expectations in the communicative look condition could lead to stronger disappointment when the puppet did not cooperate, which in turn could be reflected in children's mood. However, most children felt quite happy and there was no difference between conditions in children's mood (communicative look condition: $M=4.14, S D=1.41$; non-communicative look condition: $M=4.47, S D=0.87$; Welch's $t$-test: $\left.t=-0.49 ; d f=38, p=0.63, n_{1}=28, n_{2}=17\right)$.

Then E2 continued, "Think back to the last round of the game when the boxes appeared, but before you put your marble into the tube. In that moment, what did you first think: In which tube would [puppet's name] put her marble?" We coded whether children expected: (a) Cooperation: Children mentioned, pointed at, or touched the colorful tube, or (b) Individual play: Children mentioned, pointed to, or touched the white tube, (c) Do not know: Children explicitly said they did not know or shrugged their shoulders, or (d) Other: Children said something that did not fit into any of these categories or stayed silent. (Note that the definitions for (c) and (d) are the same for all questions below.) In the communicative look condition, $61 \%$ of children expected cooperation, 33\% expected individual play and 6\% provided other answers. In the noncommunicative look condition, $47 \%$ of children expected cooperation, $50 \%$ expected individual play and 3\% answered that they did not know. To investigate whether children's responses differed between conditions, we analyzed whether in the communicative look condition more 
children answered that they expected cooperation. Three children did not answer that they expected either cooperation or individual play and were therefore excluded from this and the next analysis. There was no significant difference between conditions $\left(\chi^{2(1)}=1.83, p=0.17\right)$. One reason for this might be that we asked the post-test questions after children had seen that the puppet had played individually. Therefore, some children might have adjusted their answers based on the puppet's actual behavior. We also looked at the whole sample to see whether children's decision in the test trial was driven by their expectations about what the puppet would do. We analyzed whether children who expected that the puppet would cooperate cooperated more themselves. Across conditions the results showed that children who expected the puppet to play cooperatively cooperated significantly more $(74 \%)$ than children who expected the puppet to play individually $\left(26 \%, \chi^{2(I)}=14.87, p<0.001\right)$. These results support the idea that children based their decision to cooperate or not on their expectations about their partner's behavior.

To investigate the reasons why children played in a certain way, E2 asked the next two questions: "Why did you expect her to do that?" and "And why did you put your marble into the white/colorful tube in the last round?" Both were coded for indications that children thought that their partner would play either cooperatively or individually: (a) I thought she saw/wanted/would play for the colorful box: Children said they thought that the puppet had seen the colorful box or that she would like to cooperate or to play together. (b) I thought she did not see/did not want/would not play for the colorful box: Children said the puppet had not seen the colorful box or she would like to play individually or put her marble into the white tube, (c) Do not know, or (d) Other. Overall, the majority of children ( $79 \%$ for the first of these two questions and $67 \%$ for second one) could not answer these two questions or provided unrelated explanations, thus no further analysis on them was conducted. 
Then, E2 asked, “How much do you like [puppet's name]?” and again showed and stepped through the smiley scale. The scores ranged from 1 ("Do you not like her at all?") to 5 (“Do you like her very much?”) With this question, we wanted to examine differences in children's liking of the puppet within the subset of children who cooperated. Stronger expectations of cooperation in the communicative look condition might result in these children liking the puppet less than children in the non-communicative look condition. However, we did not find a significant difference between conditions (Welch's $t$-test: $t=-0.30 ; d f=33 ; p=0.77$; $n_{1}=28 ; n_{2}=16$ ). Most children liked the puppet at least a bit (communicative look condition: $M$ $=4.14, S D=1.01$; non-communicative look condition: $M=4.25, S D=0.93$.) One explanation for why we did not find a difference in children's mood (in the first question) and their liking of the puppet is that these questions were not asked immediately after children found out that the puppet did not cooperate, and that any initial differences might have diminished after a short period of time.

After these questions, E2 told children that they had played well and gave them the special sticker from the test trial. Then, E2 asked them again how they felt (to make sure that no children felt bad before going back to class). Children generally felt either a little happy or very happy $(M=4.65, S D=0.75)$.

Then, E1 (without the puppet) came back into the room, and after E2 made all the prizes appear on the platform, E1 enacted for children the communicative and the non-communicative looks in turn, in counterbalanced order. While doing so she asked, "When I look at you like this, what do you think this look means?" If children did not provide a relevant answer spontaneously (i.e., mentioning her ability, or lack of ability, to see the big prize box, or mentioning cooperation or individual play), she continued and asked, "Do you think I can see the colorful box when you 
see this look?" Then, she enacted the other look and asked the same questions. For both of these questions together, for each look separately, we coded for the following responses: (a) Yes/E1 can see the big prize: Children mentioned the colorful box or referred to the collaborative choice in some other way or answered yes to the second question, or (b) No/E1 cannot see the big prize: Children mentioned the white box or the individual choice in some other way or answered no to the second question. We found that after seeing the communicative look, $80 \%$ of children answered correctly that E1 could see the big prize, and after seeing the non-communicative look $68 \%$ of children answered correctly that E1 could not see the big prize (exact binomial tests revealed that these were both significantly better than chance, $p<0.001$ and $p=0.003$, respectively). This result further supports the idea that children recognized different meanings in these two types of eye contact and interpreted them correctly.

Finally, we were interested in investigating whether children evaluated E1's play differently in the different conditions. Therefore, at the very end, E1 asked, "[Child's name], do you think I played incorrectly in the last round? Children's responses were coded as: (a) Yes (also when children said things like "a little" or "a bit"), (b) No, (c) Do not know, or (d) Other. The majority of children in both conditions answered that they did not think that E1 played incorrectly (communicative condition: 64\%; non-communicative look condition: $72 \%$ ) and there was no difference between conditions $\left(\chi^{2}(3)=2.38, p=0.50\right)$. It is perhaps puzzling that most children in the communicative look condition answered that they did not think that E1 played incorrectly. Children clearly understood that the communicative look suggested that E1 would play cooperatively so they easily could have interpreted E1's individual play as incorrect. We think it likely that children did indeed believe that E1 played incorrectly, but were simply 
unwilling to tell her this to her face. Another possibility is that children interpreted E1's decision as unfair, but not necessarily incorrect.

\subsection{Study 2}

\subsubsection{Method}

\subsubsection{Procedure}

Warm up: The materials for the warm-up game included five pairs of different colored mats $(30 \times 20 \mathrm{~cm})$ made of a thin, soft, rubbery material, which were placed on the ground, and a pack of cards $(6 \times 4 \mathrm{~cm})$, each of which displayed two colors on the same side. The goal of the game was for children and E1 to jump to the same color mat on the floor. At the beginning of every trial, E2 picked a card from the pack and showed it to the child and E1. In every trial, E1 announced which of the two colors on the card they should jump on ("Let's jump on green"). The child jumped first and then E1 followed. After three correct trials, in the next trial, E1 jumped on a different color than the one she announced. E2 waited for the child's reaction, and then he corrected E1 and encouraged children to do the same whenever E1 made a mistake: “That [E1's name]! Sometimes she does things wrong. Then you can tell her, 'That was wrong! You should do what you say you will do." Three more correct trials were followed by one incorrect trial and then two additional correct trials at the end. If in this second incorrect trial children did not spontaneously correct E1 after she jumped to the wrong mat, E2 corrected her, the game continued, and children had two additional chances if needed to correct her.

Training phase: E2 introduced the main game to children and E1, introducing the 'lake' and the 'beach.' He explained that they could decide to play individually or cooperatively. He adjusted the height of the tube according to the height of the child. E2 showed and verbally explained to children and E1 that when deciding where to jump, both players had to stand on the 
starting positions and show a 'thumbs-up' sign to each other through the tube as a signal that they were ready. Then they had to hold the tube with both hands, look at each other through the tube, and, while looking at each other, E1 would verbally suggest where they should go. Finally, E1 would count to three and clap her hands as a signal for children to decide what to do. When children and E1 played individually, E2 gave each of them a bird picture. When they played cooperatively, they opened the treasure box together, took out one container, and split the two stickers between them. In the first trial, they both played individually and in the second, they both played cooperatively. In the third trial, E2 instructed E1 to play cooperatively and children to play individually in order to demonstrate that when only one player played cooperatively, that player does not win a prize. After three training trials, as a first pre-test to see if children understood the rules, E2 asked children, "What happens if you jump to the lake and [E1] doesn't?" and "What happens if you jump to the lake and [E1] jumps as well?" If children did not answer correctly (i.e., in the former case, that they would not receive any prize, and in the latter case, that they would both receive stickers), E2 explained the game from the beginning, children and E1 repeated the same three training trials, and E2 asked these questions one more time. By this stage all children understood the rules and answered these questions correctly. After that, children played a series of individual and cooperative trials interspersed with three 'mismatch' trials in which E1 announced, "Let's jump to the lake, okay?" but after children jumped, E1 played individually, sitting on her platform. E2 waited to see if children would say something about this spontaneously, and if not then he encouraged them to protest to E1 by saying, "You can tell her: What you did was wrong! You should do what you said you would do." Then E2 corrected E1 himself. These mismatch trials in the main game, together with the mismatch trials in the warm-up game, served as a second pre-test and were designed to ensure 
that children were not too shy to protest to an adult experimenter about her behavior. One might worry that through this training children might have learned that they should protest whenever their partner does not cooperate, or whenever she does not do what she said she would do. However, it is important to note that the training was identical in both conditions, and during the test phase E1 did not say anything, so this training cannot explain our results - it was conducted simply to increase children's willingness to protest against the adult. To pass the second pre-test, children needed to correct E1 spontaneously at least once in the warm-up game (out of the four mismatch trials) and once in the main game (of the three mismatch trials).

\subsubsection{Supplementary questions and their results}

To gain more information about children's understanding of the critical test trial, we conducted more detailed coding of children's verbal responses, both in the spontaneous and the elicited response phases. Children's responses were transcribed and coded from the video recordings. A second independent observer who was naive to the hypotheses of the study coded a random sample of $25 \%$ of the children in each condition for reliability. All but two measures revealed perfect agreement (range of Cohen's $\kappa$ 's=0.64-1). The two measures (Questions 1 and 6) with a Cohen's $\kappa$ of 0.64 each had only 1 disagreement out of 18 , and these two disagreements were resolved by a third coder who was blind to condition.

We used the same coding for children's spontaneous responses and their responses to the first question, "What happened, [child's name]? Tell me" and the third question, "Do you want to say something about that to [E1's name]? Tell her what you think about what she just did. I'm sure she would be glad to know that." Children's verbal responses were coded for normative protests referring to commitment. For exploratory purposes, children who did not produce this specific type of protest were additionally given one of the following hierarchically-ordered 
codes: (a) Normative protest without reference to commitment: Children used normative vocabulary but did not refer to commitment (e.g., "You must come with me in the lake!" or "You did it wrong, I think.”), (b) Communication only: The child mentioned communication of any type (including verbal, gestural, with the eyes/looks, or with facial expressions), but did not use normative language (e.g., “[E1's name], you said that we would jump into the lake!”), (c) Interrupted normative protest: Children started to protest using normative vocabulary but did not finish the sentence (e.g., "You should... [and then the child stopped]," or "[E1's name], you must do..."), (d) Other: The child was silent or did not produce a response falling into any of the above categories. The percentage of children whose responses fell into each of these categories is shown in Table S1. Most children in both conditions did not respond to these questions with any type of protest; nor did they mention communication.

For the second question, "Did she (E1) maybe give you any sign that she would jump?"/“What sign did she give you?") and the fifth question, "Why did you expect that [E1] would jump to the lake/stay at the beach?", children's responses were categorized according to whether or not they mentioned communication (defined in the same way as above). Children in the communicative look condition mentioned communication in their answers to the second question significantly more often than children in the non-communicative look condition $(28 \%$ vs. $3 \%$, respectively; Fisher's exact test, $p<0.01$; odds ratio=13.06). A similar difference was found in children's answers to the fifth question: More children in the communicative look condition tended to mention communication there as well (19\% vs. 3\%, respectively; Fisher's exact test, $p=0.06$; odds ratio $=8.24$ ).

Children's responses to the fourth question, "Do you remember when you jumped to the lake and [E1] did not? What did you expect her to do?", were coded as: (a) Cooperation: 
Children answered that they expected E1 to cooperate (e.g., to jump, to go to the lake, to jump together), (b) Individual play: Children answered that they expected E1 to play individually (e.g., to stay on the beach, not to jump), (c) Do not know, or (d) Other. The game was set up in such a way that children in both conditions were likely to expect cooperation from E1 and therefore to cooperate themselves. The final sample included only children who cooperated, however with this question we were interested in looking at children's explicit verbal expectations in both conditions. In both conditions, $75 \%$ of children answered that they expected cooperation from E1. This shows that children in the non-communicative look condition had expectations about El's behavior as well.

At the very end of the procedure, after E1 apologized and played two successful cooperation trials with children, E2 asked the final question, "Are you [still] angry that [E1] did not always do what she said?" Children's responses were coded as: (a) Yes: Children answered positively or said that they were angry just a little bit, or (b) No: Children answered that they were not angry. The results showed that almost no children were angry at E1 at the end of the play session $(97 \%$ in the communicative look condition and $92 \%$ in the non-communicative look condition said that they were not angry). 
Table S1

Percentage of Children Who Showed Each Type of Verbal Response in Study 2.

Verbal response types during each response phase Communicative look condition
Non-communicative look condition

\section{Spontaneous response}

Normative protest referring to commitment

$39 \%$

$17 \%$

Normative protest without reference to commitment

Communication only

Interrupted normative protest

Other

\section{"What happened?"}

Normative protest referring to commitment

Normative protest without reference to commitment

Communication only

Interrupted normative protest

Other

\section{"Do you want to say something about that to [E1]?"}

Normative protest referring to commitment

Normative protest without reference to commitment

Communication only

Interrupted normative protest

Other
$0 \%$

$0 \%$

$0 \%$

$3 \%$

$11 \%$

$0 \%$

$0 \%$

$0 \%$

$89 \%$

$97 \%$
19\%

$3 \%$

$6 \%$

$56 \%$ 
Communicative eye contact signals a commitment 57

Total (across all phases) normative protest $\quad 47 \% \quad 17 \%$ referring to commitment ${ }^{2}$

${ }^{2}$ For the communicative look condition, this includes two children who used normative vocabulary and referred to the commitment in different phases. 